\title{
Simulation of a thermoelectric gas sensor that determines hydrocarbon concentrations in exhausts and the light-off temperature of catalyst materials
}

\author{
Thomas Ritter, Sven Wiegärtner, Gunter Hagen, and Ralf Moos \\ Bayreuth Engine Research Center (BERC), Zentrum für Energietechnik (ZET), Department of Functional \\ Materials, University of Bayreuth, 95447 Bayreuth, Germany \\ Correspondence: Ralf Moos (functional.materials@uni-bayreuth.de)
}

\begin{abstract}
Received: 21 July 2017 - Revised: 14 November 2017 - Accepted: 15 November 2017 - Published: 22 December 2017
\end{abstract}
\begin{abstract}
Catalyst materials can be characterized with a thermoelectric gas sensor. Screen-printed thermopiles measure the temperature difference between an inert part of the planar sensor and a part that is coated with the catalyst material to be analyzed. If the overall sensor temperature is modulated, the catalytic activity of the material can be varied. Exothermic reactions that occur at the catalyst layer cause a temperature increase that can then be measured as a sensor voltage due to the Seebeck coefficient of the thermopiles. This mechanism can also be employed at stationary conditions at constant sensor temperature to measure gas concentrations. Then, the sensor signal changes linearly with the analyte concentration. Many variables influence the sensing performance, for example, the offset voltage due to asymmetric inflow and the resulting inhomogeneous temperature distributions are an issue. For even better understanding of the whole sensing principle, it is simulated in this study by a 3-D finite element model. By coupling all influencing physical effects (fluid flow, gas diffusion, heat transfer, chemical reactions, and electrical properties) a model was set up that is able to mirror the sensor behavior precisely, as the comparison with experimental data shows. A challenging task was to mesh the geometry due to scaling problems regarding the resolution of the thin catalyst layer in the much larger gas tube. Therefore, a coupling of a 3-D and a 1-D geometry is shown. This enables to calculate the overall temperature distribution, fluid flow, and gas concentration distribution in the 3-D model, while a very accurate calculation of the chemical reactions is possible in a 1-D dimension. This work does not only give insight into the results at stationary conditions for varying feed gas concentrations and used substrate materials but shows also how various exhaust gas species behave under transient temperature modulation.
\end{abstract}

\section{Introduction}

Air pollutant emissions from passenger cars and trucks are limited by legislation; i.e., automobiles cannot be operated without exhaust aftertreatment systems. For example, nitrogen oxides in diesel exhausts are reduced in the presence of ammonia by a selective catalytic reduction (SCR) catalyst to nitrogen and water (Deutschmann and Grunwaldt, 2013). The preferred fast SCR reaction requires an equimolar ratio of nitrogen monoxide (NO) and nitrogen dioxide $\left(\mathrm{NO}_{2}\right)$, which is provided by a diesel oxidation catalyst (DOC; Koebel et al., 2000; Rexeis and Hausberger, 2009). To abate particulate matter emissions, on the other hand, diesel partic- ulate filters (DPFs) are used. With increasing soot load, the back pressure raises until the accumulated soot is burned off. To achieve this, the exhaust gas temperature is raised, e.g., by additional fuel injection. The resulting exothermic reactions in the diesel oxidation catalyst (DOC) upstream of a DPF increase the temperature of the DPF (Görsmann, 2005). Fuel injection is also an appropriate means to reduce cold start emissions. For fast heating up, unburnt exhaust components like hydrocarbons (HCs) and carbon monoxide (CO) are oxidized in the DOC to carbon dioxide $\left(\mathrm{CO}_{2}\right)$ and water $\left(\mathrm{H}_{2} \mathrm{O}\right)$, leading to a faster catalyst light-off (Russell and Epling, 2011). Since the DOC is an emission-relevant device, its correct function has to be monitored to comply with 
the onboard diagnosis (OBD) regulations (Tsinoglou et al., 2002).

Appropriate means for DOC diagnosis are, for example, temperature measurements, as the exothermic reactions in the catalyst cause a temperature increase downstream of the catalytic converter. Alternately, the oxygen content in the exhaust is monitored by lambda probes. Both techniques provide enough accuracy only in a narrow range of DOC operating points (van Nieuwstadt et al., 2005). Furthermore, the functionality of DOCs can be monitored by determining the downstream concentration of exhaust gas components using gas sensors. A broad range of sensing principles and sensor designs are disclosed in literature, but only a certain number are suitable for application in the harsh environment of automotive exhausts (Riegel, 2002; Guth and Zosel, 2004; Moos, 2005; Miura et al., 2014).

A promising sensing technique is based on the thermoelectric sensing principle as shown, e.g., by $\mathrm{Wu}$ and Micheli (2004) or recently by Wiegärtner et al. (2015). For the latter, a temperature difference between a catalyst-coated and an inert part of the sensor is measured by a screenprinted planar thermopile structure. The oxidation of hydrocarbons reaching the catalytic part causes a temperature increase, which is then measured as a Seebeck voltage over the thermopile. By modulating the overall sensor temperature, it is also possible to distinguish different hydrocarbons or to characterize catalyst materials with respect to their corresponding light-off temperatures (Hagen et al., 2017).

Several noise factors, however, affect the sensor behavior. Examples are the gas flow, the reaction chemistry on the catalyst material, or the heat transport along the substrate. Nevertheless, the basic sensing principle is well known, which allows setting up a precise finite element model to increase the understanding of the sensor behavior and to enhance the sensor performance. The present study shows how such a model is developed with finite element method (FEM) software COMSOL Multiphysics ${ }^{\circledR}$, and it compares the simulations with measurements in the test bench. For that purpose, we first explain how the sensor works and which physical effects dominate its behavior. Then, it is shown how the model is structured and which boundary conditions are applied. Since meshing was an important task, we will show how scaling issues were overcome and that eventually the measured sensor data can be reconstructed by the simulation if the sensor is exposed to a certain gas mixture. A comparison between simulations and measurements concludes this study.

\section{Sensing principle}

Thermoelectric gas sensors are based on the principle that a temperature difference forms over thermopiles caused by exothermic reactions at a gas-sensitive area of the device (Park et al., 2014; Rettig and Moos, 2007). For example, the

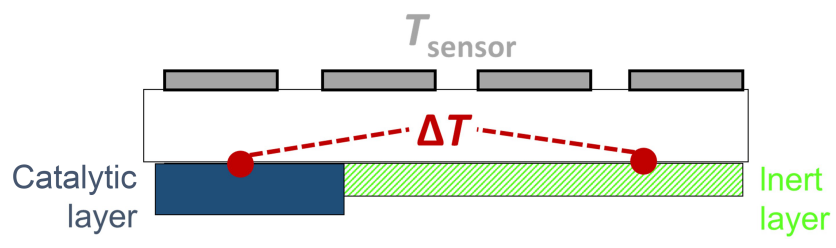

Figure 1. Cross section of the sensor device. The temperature difference $\Delta T$ is measured by a screen-printed thermopile structure. The activity of the catalytic layer is controlled by the overall sensor temperature $\left(T_{\text {sensor }}\right)$, which is provided by an integrated heating element (schematically depicted).

here-simulated sensor setup measures a temperature difference $\Delta T$ between a catalytically activated and an inert part of the sensor, as can be seen in the scheme in Fig. 1. $\Delta T$ is measured by a screen-printed thermopile structure placed under the catalytic layer and the inert layer, i.e., the thermopile determines the temperature increase caused by the exothermicity of the reactions occurring in the catalytic layer when oxidizable gas components like hydrocarbons, hydrogen, or carbon monoxide reach the sensor surface in presence of oxygen.

Then, the conversion of the gas components induces heat depending on the activity of the catalytic layer and on the rate of analytes reaching the catalytic layer. The activity depends on the applied catalyst material and on the overall sensor temperature $T_{\text {sensor, }}$ which is preset by the integrated heating element. The rate of the gas components, i.e., the number of molecules that reach the sensor surface per second, depends on the feed gas concentrations, the diffusion through the porous media, fluid flow characteristics in the form of laminar or turbulent flow, and local alignment of the device as its rotation relative to the gas flow directions can be varied.

For example, when dosing $10 \%$ oxygen in nitrogen with a varying content of propene $\left(\mathrm{C}_{3} \mathrm{H}_{6}\right)$, one observes that the sensor signal rises linearly with the propene concentration when the overall sensor temperature is about $600^{\circ} \mathrm{C}$. The temperature difference $\Delta T$ is not only determined by Seebeck coefficients of the used thermocouple materials (which are temperature dependent), but it is also affected by other parameters like a temperature gradient induced by the layout of the screen-printed heater or by the thermal conductivity of the substrate materials, which may be alumina $\left(\mathrm{Al}_{2} \mathrm{O}_{3}\right.$, $\left.\lambda_{\mathrm{Al}_{2} \mathrm{O}_{3}}\left(600^{\circ} \mathrm{C}\right) \approx 10 \mathrm{~W}(\mathrm{~m} \mathrm{~K})^{-1}\right)$ or low-temperature cofired ceramics $\left(\mathrm{LTCC}, \lambda_{\mathrm{LTCC}}=2.5 \mathrm{~W}(\mathrm{~m} \mathrm{~K})^{-1}\right.$; Kita et al., 2015). The sensor signal change, i.e., the output voltage of the thermopile, should be as high as possible so that small analyte concentration changes or analyte components that are only a little reactive can be determined. The output voltage depends on the Seebeck coefficient of the thermocouple materials and on the number of thermocouples that are connected in series, as was shown before, for example, in Casey et al. (2003) and Houlet et al. (2008). 


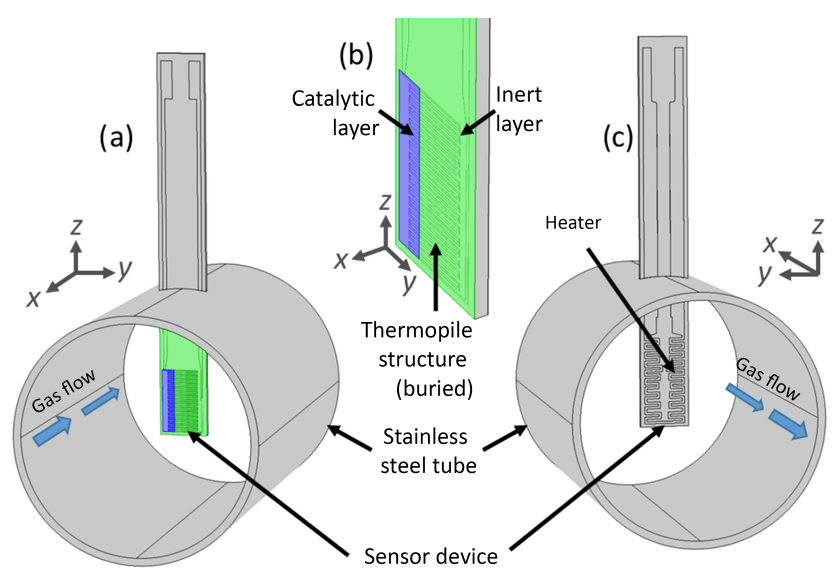

Figure 2. Geometry as implemented in COMSOL Multiphysics ${ }^{\circledR}$. (a) View of the front of the setup used for measurements. (b) Closer view of the front of the sensor surface with thermopile structure buried under the inert (green domain) and catalytically activated layer (blue domain). (c) View of the reverse side of the sensor surface with heating element. The blue arrows depict the gas flow direction.

The catalytic activity depends on the overall sensor temperature $T_{\text {sensor }}$, which can be set by the integrated heater. Since $T_{\text {sensor }}$ can be modulated from room temperature to about $650{ }^{\circ} \mathrm{C}$, oxidizable gas components in the feed gas mixture can be distinguished by their corresponding light-off temperature (Hagen et al., 2017).

It can be seen that there are many factors influencing the finally measured sensor voltage, but on coupling all these physical effects including fluid flow, gas diffusion, heat transfer, chemical reactions, and electrical properties, it should be possible to simulate the sensor mechanisms and predict the sensor signal.

\section{Boundary conditions}

To include all dominating physical effects, a model was set up that mirrors the real measurement setup as far as possible. The implemented geometry can be seen in Fig. 2, wherein the sensor device consisting of an alumina or LTCC substrate is assembled in a stainless steel tube. Therefore, a part of the device does not face the analyzed gas mixture but is in contact with the surrounding atmosphere.

At one opening of the tube, a constant volumetric flow rate is assumed while the fluid leaves the tube with an outflow condition, meaning that no further gas velocity change at constant pressure can occur.

Since there is no flow perpendicular to the tube walls, a radial symmetric gas velocity profile ( $U$ profile) forms at the inlet. The gas velocity vector $\boldsymbol{u}$ and the pressure $p$ in the tube or around the sensor device are calculated according to Eq. (1), which is deduced from Navier-Stokes equations
(Batchelor, 2000):

$\rho_{i} \frac{\delta \boldsymbol{u}}{\delta t}+\rho_{i} \cdot \boldsymbol{u} \cdot \operatorname{grad} \boldsymbol{u}=-\operatorname{grad} p+\mu \cdot \operatorname{div}(\operatorname{grad} \boldsymbol{u})$.

Here, the temperature dependent density $\rho_{i}$ and the dynamic viscosity $\mu$ are calculated under the assumption of a carrier fluid consisting of $10 \%$ oxygen in nitrogen. The left part of the equation corresponds to inertial forces, while the forces arising from pressure and viscous changes are represented by the terms on the right. In the whole setup, heat transfer was determined by assuming natural convection at the tube boundaries, as well as on the sensor surfaces outside of the tube. The fluid flows into the tube at room temperature and is heated by the sensor with the dissipated power in the heating element. Another heat source $Q$, which influences the temperature $T$ in the setup, is the catalytic layer where exothermic heat from the analyte combustion occurs. Basic energy balances yield to the temperature distribution in Eq. (2) (Bird et al., 2007):

$\rho_{i} \cdot c_{\mathrm{p}, i} \cdot \frac{\delta T}{\delta t}+\rho_{i} \cdot c_{\mathrm{p}, i} \cdot \boldsymbol{u} \cdot \operatorname{grad}(T)-\lambda_{i} \cdot \operatorname{div}(\operatorname{grad} T)=Q$.

The index $i$ represents the different materials. The heat capacity at constant pressure $c_{\mathrm{p}, i}$ and thermal conductivity $\lambda_{i}$ are material constants. The latter has to be adjusted for the porous catalytically active layer according the volume fraction of solid and gaseous proportions. The terms in Eq. (2) correspond from left to right to the time dependency, temperature gradient caused by convection (which vanishes in solids), temperature gradient caused by diffusion, and the source term that contains, in this case, the induced heat by the heater and the exothermicity.

In the experiments, i.e., when measuring, the sensor device is heated up to $650^{\circ} \mathrm{C}$ to provide sufficient reaction kinetics. The heater power is impressed by the screen-printed heater tracks on the reverse side of the device. To simulate the temperature of the sensor device, two approaches were used. On the one hand, the overall sensor temperature was set by a constant temperature on the reverse side of the device. The other approach was to implement the whole heater design and to calculate Joule heating by applying a certain voltage to the heater tracks (as is done in the measurements).

To save computational time, the overall sensor temperature $T_{\text {sensor, }}$ which is set by the heater, was modeled in a first step by assuming a constant temperature on the reverse side of the device. Then, the temperature distribution in the whole setup is modeled sufficiently accurately, but to resolve the small temperature changes due to the exothermic reactions in the catalytic layer it is necessary to implement the whole heater design and the dissipated electrical power that emerges due to the Joule resistive heating in the heater tracks, as can be seen in Fig. 3.

In Fig. 3, the temperature on a line at the front side of the device is shown for the assumption of a constant sensor 


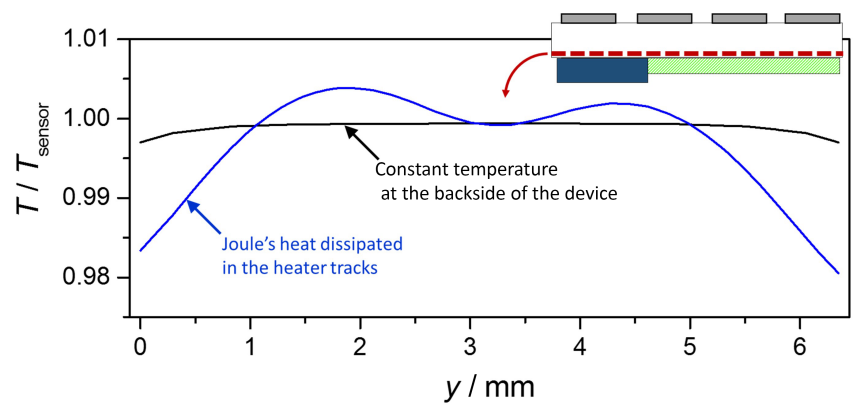

Figure 3. Calculated temperature distribution depending on the overall sensor temperature $T_{\text {sensor }}$ on a line across the whole width $(6.35 \mathrm{~mm})$ of the device on assuming a constant temperature on the reverse side of the device or implementing the heater. The red dotted line in the scheme on the upper right illustrates where the temperature is evaluated.

temperature on the reverse side of the sensor and on implementing the whole heater design and calculating the resistive losses in the conductive tracks. Then, the temperature gradient along the spatial coordinate is rather small, with a constant temperature condition. If the whole heater design is implemented and Joule heating is calculated by applying a certain voltage to the conductive tracks, the temperature deviation from target temperature $T_{\text {sensor }}$ is up to $8 \mathrm{~K}$ (in the case of $T_{\text {sensor }}=600^{\circ} \mathrm{C}$ ). Two maxima are formed in the temperature curve because the evaluation line crosses two heater tracks. The dissipated electrical power density $Q_{\text {el }}$ can be calculated from Eq. (3), wherein the electrical conductivity is denoted by $\sigma$ and $\phi . \phi$ stands for the electric potential (Haslach, 2011):

$Q_{\mathrm{el}}=-\sigma \cdot|\operatorname{grad} \phi|^{2}$

Even the thin thermocouples influence the temperature distribution a little due to their own thermal conductivity, which can also be deduced from simulation. However, it turned out that this influence can be neglected. Another issue that has to be taken into account when calculating the temperature difference as a result of the exothermicity is that the heating power is controlled by a proportional-integral-derivative (PID) controller. Since the whole device is heated up by the exothermic reactions at the catalytically active layer (if reducing components are in the gas to be analyzed), the controller reduces the electrical power to reach again the setpoint temperature $T_{\text {sensor }}$. If the analyte concentration and consequently the produced exothermicity are high, neglecting the electrical power change in the simulation would cause deviating results compared to the measurements. Therefore, the temperature is set constant when controlling the heater voltage $U_{\text {heater }}$ for the $n$th time step $t_{n}$ according to Eq. (4)
(O’Dwyer, 2009).

$$
\begin{aligned}
U_{\text {heater }}\left(t_{n}\right) & =K_{\mathrm{p}} \cdot\left[e\left(t_{n}\right)+\frac{1}{T_{\mathrm{I}}} \int_{0}^{t_{n}} e\left(t^{*}\right) \mathrm{d} t^{*}\right. \\
& \left.+T_{\mathrm{D}} \cdot \frac{e\left(t_{n}\right)-e\left(t_{n-1}\right)}{t_{n}-t_{n-1}}\right]+U_{\text {heater }}\left(t_{n-1}\right)
\end{aligned}
$$

Here, the error value $e\left(t_{n}\right)$ is the difference between the setpoint temperature $T_{\text {sensor }}$ and the calculated temperature at the front side of the device. This temperature is adjusted on setting suitable PID coefficients as here denoted by the proportional term $K_{\mathrm{p}}$, the integration time $T_{\mathrm{I}}$, and the derivative time $T_{\mathrm{D}}$. If now the temperature raises due to the exothermicity, the heater voltage is lowered, and again, the setpoint is reached.

In order to calculate the concentrations of the gas components in the whole setup, it is assumed that a constant feed gas concentration $c_{k, 0}$ occurs at the inlet of the tube. For those gas components that leave the tube, no further concentration change is adopted at the outlet so that the first derivative of the concentration gets to zero. The concentration $c_{k}$ for each gas component $k$ is calculated according to the convection-diffusion equation (Baliga and Patankar, 1980):

$\frac{\delta c_{k}}{\delta t}+\boldsymbol{u} \cdot \operatorname{grad} c_{k}-D_{k} \cdot \operatorname{div}\left(\operatorname{grad} c_{k}\right)=R_{k}$.

The rate expression $R_{k}$ is always zero with the exception of the catalytically active layer at which the reactions occur. Analogously to the heat transfer calculation, the terms from left to right correspond to the time dependency and concentration gradient caused by convection and diffusion, while the term on the right stands for a source (or sink) term. The diffusion coefficients $D_{k}$ are determined depending on their diffusion coefficient in oxygen $D_{k, \mathrm{O}_{2}}$ and in nitrogen $D_{k, \mathrm{~N}_{2}}$ and its mole fraction $y_{k}$ (Fairbanks and Wilke, 1950):

$D_{k}=\left(1-y_{k}\right) /\left(\frac{y_{\mathrm{O}_{2}}}{D_{k, \mathrm{O}_{2}}}+\frac{y_{\mathrm{N}_{2}}}{D_{k, \mathrm{~N}_{2}}}\right)$.

We assume that the diffusion coefficient of the $k$ th gas component is only affected by the presence of oxygen and nitrogen and not by other components that are formed, for example, at the catalytic layer since their concentration is rather small compared to nitrogen and oxygen. Then, the diffusion coefficients $D_{k, \mathrm{O}_{2}}$ and $D_{k, \mathrm{~N}_{2}}$ can be determined according to Eqs. (7) and (8), if the molecular masses $M_{k}$, the average collision diameters $\sigma_{k, \mathrm{~N}_{2}}$ and $\sigma_{k, \mathrm{O}_{2}}$, and the temperaturedependent collision integrals $\Omega$ are known.

$$
\begin{aligned}
& D_{k, \mathrm{O}_{2}}=1.858 \cdot 10^{-3} \cdot \sqrt{M_{k}^{-1}+M_{\mathrm{O}_{2}}^{-1}} \cdot T^{\frac{3}{2}} /\left(p \cdot \sigma_{k, \mathrm{O}_{2}}^{2} \cdot \Omega\right), \\
& D_{k, \mathrm{~N}_{2}}=1.858 \cdot 10^{-3} \cdot \sqrt{M_{k}^{-1}+M_{\mathrm{O}_{2}}^{-1}} \cdot T^{\frac{3}{2}} /\left(p \cdot \sigma_{k, \mathrm{~N}_{2}}^{2} \cdot \Omega\right),
\end{aligned}
$$

For the catalytic layer, the diffusion coefficients are adjusted according to the porosities $\varepsilon$ and the tortuosities $\tau$ with 
$\tau=\varepsilon^{-1 / 3}$, leading to effective diffusion coefficients $D_{k \text {,eff }}$ (Millington, 1959):

$$
D_{k, \mathrm{eff}}=\varepsilon^{4 / 3} \cdot D_{k}
$$

The rate expression factors $R_{k}$ for each species are calculated by determining the reaction rates $r_{j}$ for each reaction $j$ according to a modified Arrhenius equation to meet the temperature dependence over the wide temperature band that is used later for the overall sensor temperature modulation from room temperature to $650^{\circ} \mathrm{C}$. The pre-exponential factors $A_{j}$, the temperature exponents $n_{j}$, and the activation energies $E_{\mathrm{a}, j}$ are adjusted with respect to the corresponding exothermicities that occur at the catalytically activated layers determined in measurements when analyte concentrations and the overall sensor temperatures are varied (Eq. 10). The forward reaction rates $r_{\mathrm{f}, j}$ are then calculated for the reactions shown in Eqs. (11)-(13).

$r_{\mathrm{f}, j}=A_{j} \cdot T^{n_{j}} \cdot \exp \left[-E_{\mathrm{a}, j} /(R \cdot T)\right]$,

$\mathrm{C}_{3} \mathrm{H}_{8}+5 \mathrm{O}_{2} \Longrightarrow 3 \mathrm{CO}_{2}+4 \mathrm{H}_{2} \mathrm{O} \quad(j=1)$

$2 \mathrm{C}_{3} \mathrm{H}_{6}+9 \mathrm{O}_{2} \Longrightarrow 6 \mathrm{CO}_{2}+6 \mathrm{H}_{2} \mathrm{O} \quad(j=2)$,

$2 \mathrm{H}_{2}+\mathrm{O}_{2} \Longrightarrow 2 \mathrm{H}_{2} \mathrm{O} \quad(j=3)$

By assuming a net forward reaction, the reaction rates and rate expression factors can be described by Eqs. (14) and (15) if the analyte concentrations and the stoichiometric numbers $v_{j, k}$ are known.

$$
\begin{array}{r}
r_{j}=r_{\mathrm{f}, j} \cdot c_{k} \cdot c_{\mathrm{O}_{2}}, \\
R_{k}=\sum_{j} v_{j, k} \cdot r_{j}
\end{array}
$$

From these parameters, the occurring exothermicities $Q_{j}$ can be calculated by inserting the enthalpies of the reactions $\Delta H_{j}$ into the following expression:

$Q_{j}=-r_{j} \cdot \Delta H_{j}$.

Therefore, the standard enthalpy of formation $h_{k}$ must be known for each temperature, which is here calculated in accordance to the NASA format, where the thermodynamic and transport properties for each species can be determined with a polynomial function. Here, we used the same coefficients as they are given in McBride et al. (1993). Then, the reaction enthalpies of $\Delta H_{j}$ are determined by considering the stoichiometric numbers $v_{j, k}$ :

$\Delta H_{j}=\sum_{k} v_{j, k} \cdot h_{k}$.

Initial data and approaches for modeling the reaction kinetics at a catalyst can be found, for instance, in Kirchner and Eigenberger (1997), Chatterjee et al. (2001), Kočí et al. (2006), and Ramanathan and Sharma (2011).

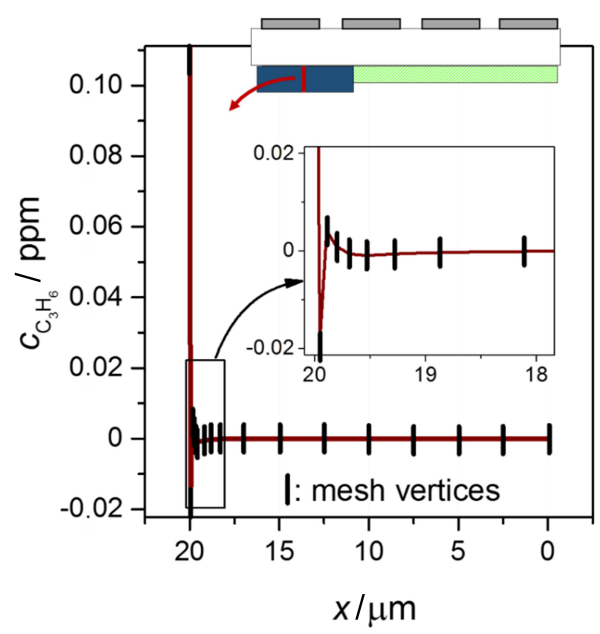

Figure 4. Calculated propene concentration for a minimum of mesh elements evaluated on the red line through the thickness of the catalytically activated layer. A negative concentration is calculated because of the high reaction rate and too few mesh elements. The scheme at the top illustrates where the concentration is evaluated.

\section{Coupling of two geometries}

It turned out that meshing the whole geometry is quite challenging due to the fact that the thin catalyst layer is 1000 times smaller than the stainless steel tube diameter. Filling the area around the sensor device with suitable mesh elements is only possible if one reduces the mesh vertices along the thickness of the catalyst layer to a minimum. Then, due to the high reaction rates, a problem occurs. It is illustrated in Fig. 4. The majority of the analyte is converted at the surface of the catalyst, so reducing the mesh elements causes negative concentrations, possibly because the distance between the mesh element at the catalyst surface and the next one in the layer is too large. Due to the high reaction rates, the calculated concentration differences according to Eq. (5) are larger than the absolute concentration of the analyte. This yields the negative concentration.

Therefore, another method to calculate the analyte concentration in the catalyst layer was applied. For that purpose, a second geometry that is coupled to the whole setup in Fig. 2 was used. This second geometry can be, for example, a 1-D geometry that represents the thickness of the catalytic layer. Then, the average gas component concentration at the surface of the catalytic layer, which is calculated in the 3-D geometry without the rate expression $R_{k}$ is set in the 1-D geometry as the inlet boundary condition. Again, the gas components' distribution is calculated by Eq. (5), while the gas velocity can be assumed to be zero. From that simplified geometry, the exothermicity and the concentrations of the converted gas components can be derived, which are then returned to the 3-D geometry. Since, the effects occur mostly at the surface of the catalytic layer, it can be assumed that the catalytic layer 


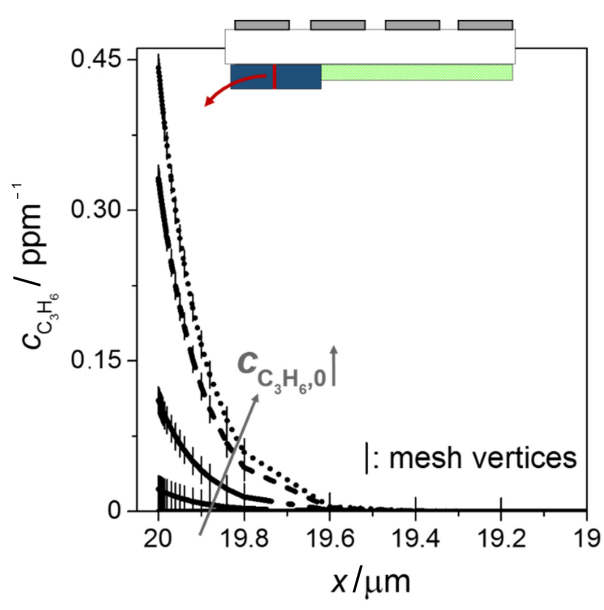

Figure 5. Calculated propene concentration for different feed gas concentrations in the first micron of the catalyst layer on coupling a 3-D and 1-D geometry. By this coupling, a very fine resolution of the catalytic layer thickness can be achieved. The scheme at the top should illustrate where the concentration is evaluated.

borders in the 3-D geometry represent a sink (or a source) for the gas components, while the heat of reaction is a function of the catalyst layer thickness.

It is the advantage of this calculation method that the catalyst layer can be resolved well enough, as the mesh vertices used in the 1-D geometry do not affect the mesh in the 3-D geometry where the catalyst layer now can be meshed coarser. This solves the issue of negative concentrations, as shown in Fig. 5, wherein the concentration distribution for different feed gas concentrations in the first micron of the catalyst layer is shown.

An iterative exchange of this coupled system is used for the solution of both geometries. Then, the overall temperature distribution, the fluid flow, the electrical properties, and the gas concentration distribution can be calculated in the 3-D geometry (with a coarser mesh and a reduced computational time), while the more accurate gas concentration distribution and the chemical reactions in the catalyst layer can be derived separately but simultaneously in the 1-D geometry. The accuracy of this method may be further increased, for instance, by replacing the catalyst layer by a 2-D geometry or another 3-D geometry. This, however, comes along with a higher computational time. This trade-off has to be solved (as always when setting up FEM models). In this study, only the results of the 3-D-1-D system are shown, since its accuracy is high enough as will be shown below.

\section{Results for stationary conditions}

As mentioned before, the reaction kinetics parameters were adjusted until the measured exothermicity could be simulated by the model. Therefore, the overall sensor temperature

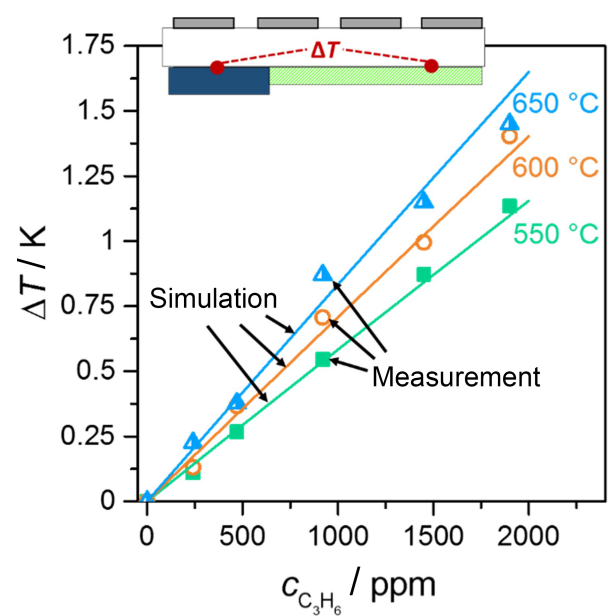

Figure 6. Measured (points) and simulated (lines) temperature difference $\Delta T$ between the catalytically activated and the inert part of the sensor when the propene feed gas concentrations and the overall sensor temperature were varied (stationary conditions). The inset scheme illustrates at which points the temperature difference was evaluated.

$T_{\text {sensor }}$ and the feed gas concentrations $c_{k, 0}$ were varied to find one dataset for each single analyte.

The measurements at stationary conditions were conducted as already described in detail in Wiegärtner et al. (2015), while a constant overall sensor temperature was set and the analyte concentration (here propene) was changed stepwise from 0 to about $2000 \mathrm{ppm}$. The measured sensor signal was offset corrected and converted to the corresponding temperature signal. Since a gold/platinum thermocouple was screen printed, a Seebeck coefficient of about $19 \mu \mathrm{V} \mathrm{K}^{-1}$ (according to the here-used sensor temperatures) must be applied (Bentley, 1998). Then, the linear correlation between temperature difference and analyte concentration can be seen for different overall sensor temperatures in Fig. 6. The reaction kinetics parameters are deduced from these measured values starting with an initial estimation, which is derived from literature for similar materials, and adjusting them until all sensor temperatures and analyte concentrations can be simulated as can be seen by the straight lines in Fig. 6 .

This obtained dataset for reaction kinetics can now be used for further investigations. In Wiegärtner et al. (2015), the substrate material was modified from alumina to LTCC due to the lower thermal conductivity of LTCC. This increased the sensor voltage, since there is less short-circuiting heat flux from the catalytic layer to the inert part of the device. As can be seen in Fig. 7, this mechanism can also be simulated by the model. No further adjustment of the reaction kinetic parameters was necessary for that. Now, the model can be applied to further improve the sensor performance at stationary conditions to vary the geometry, thermopile position, materials, etc. All constants, as they were used for modeling, are given in Table 1. Data including reaction kinetics as the pre- 


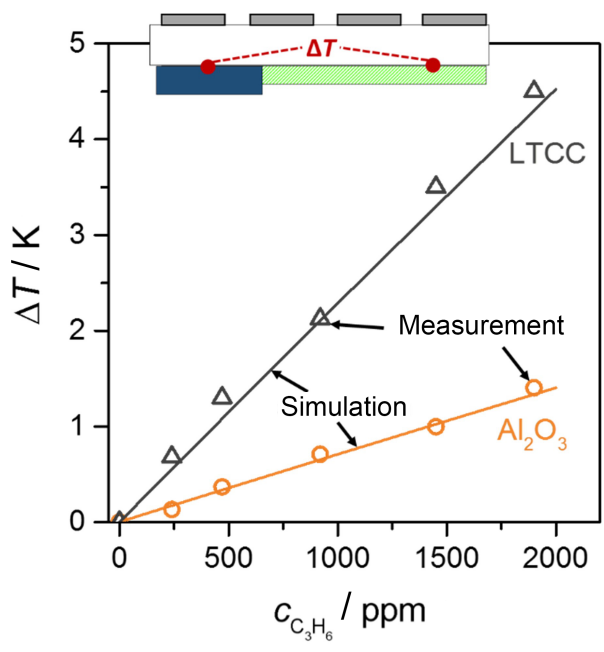

Figure 7. Measured (points) and simulated (lines) temperature difference $\Delta T$ between the catalytically activated and the inert part of the sensor when the propene feed gas concentrations and the sensor materials were varied (stationary conditions). The sensor temperature was kept constant at $600^{\circ} \mathrm{C}$. The inset scheme illustrates at which points the temperature difference was evaluated.

exponential factor, activation energy, and temperature exponents for reaction were obtained from measurements. Mole fractions, flow rate, and PID parameters were chosen as they were used in the measurements. Material properties are averaged data from unpublished measurements, literature data, and data sheets. The origin of the data is referenced in Table 1.

\section{Results for transient conditions}

The sensor device can also be used to distinguish between different analytes. Therefore, the overall sensor temperature was modulated from room temperature to $650^{\circ} \mathrm{C}$ as depicted in Fig. 8. The sensor signal mirrors the light-off temperatures of the corresponding analytes. Very similar measurements can be found in Hagen et al. (2017). There, the device was applied as a tool for catalyst material characterization. For that purpose, the non-inert area was coated with an unknown catalyst material to determine the light-off behavior of these materials.

The model as developed above can also simulate these results. The overall sensor temperature $T_{\text {sensor }}$ is modulated by defining a time-dependent setpoint temperature to the PID controller as is shown in Fig. 8. With increasing temperature, the activity of the catalytically active layers increases as well, and the analytes are oxidized according to Eqs. (11)-(13). When all analytes are oxidized at the catalyst contacts, the temperature difference $\Delta T$ reaches a saturation value. Below this temperature, i.e., before full conversion occurs, $\Delta T$ increases with increasing activity of the catalytic layer. During the cooling phase, the temperature difference $\Delta T$ should

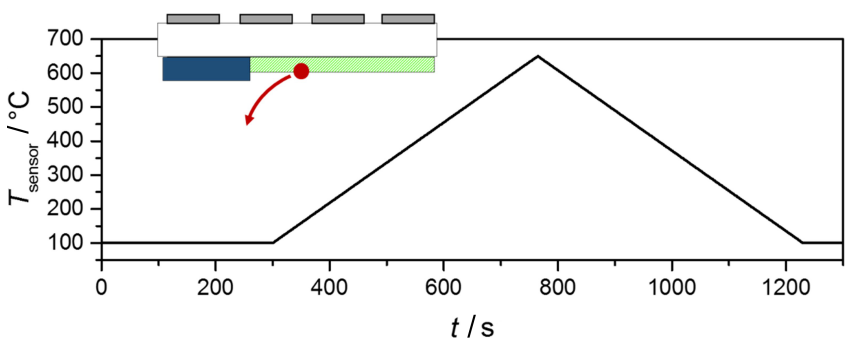

Figure 8. Modulation of the overall sensor temperature $T_{\text {sensor }}$ over time as implemented in the simulation. The inset scheme illustrates at which point the temperature was evaluated.

return to zero without a hysteresis. This behavior can be seen in Fig. 9 for propene as the analyte (here with LTCC as the substrate material of the device). The light-off temperature (temperature of $50 \%$ conversion) for propene at this catalyst material can then be determined to about $200^{\circ} \mathrm{C}$.

Using the dataset from the stationary conditions, the simulations for all gas species agree also very well with the measured values even under these transient conditions. Even the very slight hysteresis for propene that occurs around the light-off temperature can be seen in the simulation. The reason for the hysteresis is the high reactions rates due to the exothermicity that keeps the reaction alive even at, compared to the heating phase, lower temperatures. If one changes the analyte to a gas species with a lower reactivity, for instance, to propane $\left(\mathrm{C}_{3} \mathrm{H}_{8}\right)$, a higher light-off temperature occurs. Figure 9 shows clearly that propane conversion starts at much higher temperature. For the here-used material, at least $400^{\circ} \mathrm{C}$ is required. Due to the lower reactivity of propane and the 5 times higher concentration compared to the propene data (5000 ppm vs. $1000 \mathrm{ppm})$, the signal does not saturate in the investigated temperature range, i.e., not all propane molecules are being converted at the catalyst surface. This behavior is also mirrored by the described model; even the fact that no hysteresis occurs can be seen. It is also possible to simulate the reaction behavior of $5000 \mathrm{ppm}$ hydrogen, where the conversion starts at $100^{\circ} \mathrm{C}$, increases constantly with temperature, and does not saturate in the investigated temperature range. Again, no hysteresis is seen both in the simulations and in the measurements.

The simulation can also provide a better understanding of the shape of the three temperature difference $\Delta T$ profiles over the sensor temperature $T_{\text {sensor }}$. When dosing propene, there is no temperature difference $\Delta T$ at low temperatures since the activity of the reaction is too small. Then, with increasing sensor temperature, the reaction rate increases drastically, leading to a sharp exothermicity rise until the temperature difference $\Delta T$ saturates. This is because all propene molecules reaching the surface of the catalytically active layer are immediately converted (Eq. 12), while postdiffusion of further propene is comparably low. However, the total flux magnitude for hydrogen at the surface of the cat- 
Table 1. Parameters used for modeling of the sensing principle.

\begin{tabular}{|c|c|c|c|c|c|}
\hline Parameter & Description & & Value or function & Unit & Ref. \\
\hline$A_{j}$ & $\begin{array}{l}\text { Pre-exponential factor } \\
\text { for reaction }\end{array}$ & $\begin{array}{l}j=1 \\
j=2 \\
j=3\end{array}$ & $\begin{array}{r}5.296 \times 10^{10} \\
4.85 \times 10^{13} \\
2.8 \times 10^{13}\end{array}$ & $\mathrm{~m}^{3}(\mathrm{~K} \mathrm{~s} \mathrm{~mol})^{-1}$ & 1 \\
\hline$c_{\mathrm{p}, i}$ & $\begin{array}{l}\text { Heat capacity at constant } \\
\text { pressure of }\end{array}$ & $\begin{array}{l}\text { alumina } \\
\text { the carrier fluid } \\
\text { the catalyst material } \\
\text { the inert layer } \\
\text { LTCC } \\
\text { stainless steel }\end{array}$ & $\begin{array}{r}730 \\
f(T) \\
1100 \\
800 \\
989 \\
500\end{array}$ & $\mathrm{~J}(\mathrm{~kg} \mathrm{~K})^{-1}$ & 2 \\
\hline$E_{\mathrm{a}, j}$ & Activation energy & $\begin{array}{l}j=1 \\
j=2 \\
j=3\end{array}$ & $\begin{array}{r}8.2 \times 10^{4} \\
5 \times 10^{3} \\
2.4 \times 10^{4}\end{array}$ & $\mathrm{~J} \mathrm{~mol}^{-1}$ & 1 \\
\hline$h_{k}$ & Standard enthalpy of form & tion & $f(T)$ & $\mathrm{J} \mathrm{mol}^{-1}$ & 3 \\
\hline$K_{\mathrm{p}}$ & Proportional term & & 0.005 & $\mathrm{~V} \mathrm{~K}^{-1}$ & 4 \\
\hline$M_{k}$ & Molar mass of & $\begin{array}{l}\text { carbon dioxide } \\
\text { hydrogen } \\
\text { nitrogen } \\
\text { oxygen } \\
\text { propene } \\
\text { propane } \\
\text { water }\end{array}$ & $\begin{array}{r}44.01 \\
2 \\
28.01 \\
31.99 \\
42.08 \\
44.1 \\
18.02\end{array}$ & $\mathrm{~g} \mathrm{~mol}^{-1}$ & 5 \\
\hline$n_{j}$ & $\begin{array}{l}\text { Temperature exponent } \\
\text { for reaction }\end{array}$ & $\begin{array}{l}j=1 \\
j=2 \\
j=3\end{array}$ & $\begin{array}{r}0.4 \\
-1.92 \\
-1.1\end{array}$ & 1 & 1 \\
\hline$T_{\mathrm{D}}$ & Derivative time & & 1 & $\mathrm{~ms}$ & 4 \\
\hline$T_{\mathrm{I}}$ & Integration time & & 600 & $\mathrm{~s}$ & \\
\hline$y_{\mathrm{O}_{2}}$ & Mole fraction of oxygen & & 0.1 & 1 & \\
\hline$y_{\mathrm{N}_{2}}$ & Mole fraction of nitrogen & & $f\left(y_{\mathrm{O}_{2}}, y_{\mathrm{C}_{3} \mathrm{H}_{6}}, y_{\mathrm{C}_{3} \mathrm{H}_{8}}, y_{\mathrm{H}_{2}}\right)$ & 1 & \\
\hline$\dot{V}$ & Volumetric flow rate & & 2 & $\mathrm{~L}_{\min }^{-1}$ & \\
\hline$\varepsilon$ & Porosity & & 0.1 & 1 & \\
\hline$\lambda_{\mathrm{i}}$ & Thermal conductivity of & $\begin{array}{l}\text { alumina } \\
\text { the carrier fluid } \\
\text { the catalyst material } \\
\text { the inert layer } \\
\text { LTCC } \\
\text { stainless steel }\end{array}$ & $\begin{array}{r}f(T) \\
f(T) \\
0.44 \\
3 \\
2.5 \\
15\end{array}$ & $\mathrm{~W}(\mathrm{~m} \mathrm{~K})^{-1}$ & 6 \\
\hline$\mu$ & Dynamic viscosity of the & arrier fluid & $f(T)$ & $\mathrm{Pas}$ & 7 \\
\hline$\rho_{\mathrm{i}}$ & Density of & $\begin{array}{l}\text { alumina } \\
\text { the carrier fluid } \\
\text { the catalyst material } \\
\text { the inert layer } \\
\text { LTCC } \\
\text { stainless steel }\end{array}$ & $\begin{array}{r}3965 \\
f(T p) \\
3900 \\
3000 \\
3100 \\
7900\end{array}$ & $\mathrm{~kg} \mathrm{~m}^{-3}$ & 8 \\
\hline
\end{tabular}


Table 1. Continued.

\begin{tabular}{|c|c|c|c|c|c|}
\hline Parameter & Description & & Value or function & Unit & Ref. \\
\hline$\sigma$ & Electrical conductivity & of platinum & $f(T)$ & $\mathrm{S} \mathrm{m}^{-1}$ & 9 \\
\hline \multirow[t]{7}{*}{$\sigma_{k}$} & \multirow{7}{*}{ Collision diameter of } & carbon dioxide & 3.941 & \multirow[t]{7}{*}{$\AA$} & \multirow[t]{7}{*}{10} \\
\hline & & hydrogen & 2.92 & & \\
\hline & & nitrogen & 3.798 & & \\
\hline & & oxygen & 3.467 & & \\
\hline & & propene & 4.678 & & \\
\hline & & propane & 5.118 & & \\
\hline & & water & 2.641 & & \\
\hline$\Omega$ & \multicolumn{2}{|l|}{ Collision integral } & $f(T)$ & \multicolumn{2}{|l|}{1} \\
\hline \multicolumn{6}{|c|}{$\begin{array}{l}\text { Obtained from measurements. }{ }^{2} \text { Tan et al. (1995); Verein Deutscher Ingenieure (2010); Bhatia et al. (2009); Kockmann } \\
\text { al. (2013); Mills et al. (2004). }{ }^{3} \text { McBride et al. (1993). }{ }^{4} \text { As used in measurements. }{ }^{5} \text { Poling et al. (2001). }{ }^{6} \text { Kita et } \\
\text { l. (2015); Verein Deutscher Ingenieure (2010); Groppi and Tronconi (1996); Cruickshank (2017); Mills et al. (2004). } \\
\text { Verein Deutscher Ingenieure (2010). }{ }^{8} \text { Munro (1997); Verein Deutscher Ingenieure (2010); Mohanram et al. (2006); } \\
\text { Gills et al. (2004). }{ }^{9} \text { Obtained from measurements. }{ }^{10} \text { Poling et al. (2001); Bird et al. (2007). }\end{array}$} \\
\hline
\end{tabular}

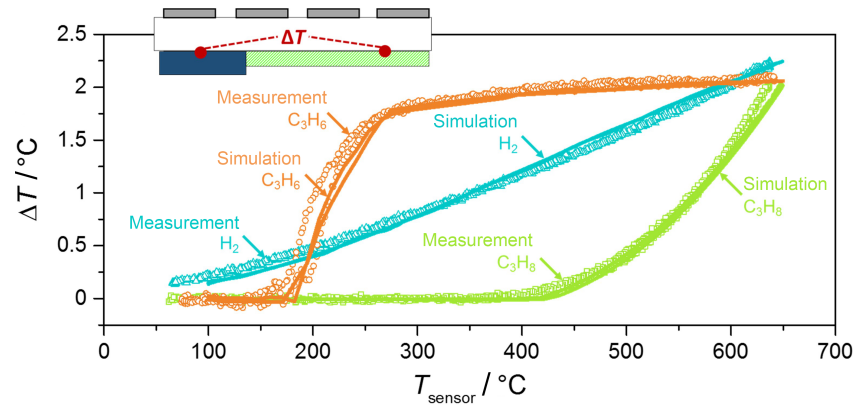

Figure 9. Measured (points) and simulated (lines) temperature difference $\Delta T$ between the catalytically activated and inert parts of the sensor when the overall sensor temperature was modulated, as shown in Fig. 8. The curves for different analytes $\left(1000 \mathrm{ppm} \mathrm{C}_{3} \mathrm{H}_{6}\right.$, $5000 \mathrm{ppm} \mathrm{C}_{3} \mathrm{H}_{8}$, or $5000 \mathrm{ppm}_{2}$ in $10 \% \mathrm{O}_{2}$ and $\mathrm{N}_{2}$ ) differ markedly; however, these differences are mirrored by the simulations. The inset scheme illustrates at which points the temperature difference was evaluated.

alytically active layer is, according to the simulations, about 10 times higher compared to propene and propane. This explains that no saturating temperature difference $\Delta T$ has been reached. Up to a sensor temperature of about $600^{\circ} \mathrm{C}$, the maximum temperature difference $\Delta T$, that is reached when dosing hydrogen, is smaller than when using propene, despite a higher concentration for $\mathrm{H}_{2}$ being used. According to the simulation, this can be explained by the 10 times smaller reaction enthalpy. The higher light-off temperature of propane is given by the reaction kinetics parameter, but due to the higher total flux magnitude and enthalpy of reaction (compared with propene) a higher maximum temperature difference $\Delta T$ is calculated, while a less sharp transition from zero to the maximum temperature difference can already be seen in the graph in Fig. 9.
It can be seen that the model is able to describe also the behavior of the sensor device at transient conditions. It is noteworthy to mention that even for this wide temperature range, only a single dataset was used (Table 1). In order to model a hysteresis, as is known for carbon monoxide due to catalyst poisoning, the model needs further adjustments. Poisoning of catalyst sites can only be described if one adopts an additional equation for surface coverage that partly inhibits the reaction rates according to Eq. (14). Then, however, it should also be possible to calculate the sensor behavior when admixing CO to the feed gases, as shown, for instance, in Hagen et al. (2017). Probably, by implementing the coverage of the catalyst, predictions can be made with respect to the content of active catalytic sites, as one could vary the platinum load of the here-used catalyst without performing a rather expensive measurement series.

\section{Conclusion and outlook}

This work describes a finite element (FE) model that can be used to simulate the behavior of an entire thermoelectric gas sensor device. The core of this model is the coupling of all the influencing physical and physicochemical effects. Thereby, the calculated system has to be divided into two geometries that are coupled to resolve sufficiently the comparatively thin catalyst layer. Under stationary conditions, the model is able to simulate the measured sensor behavior for different sensor materials, analyte concentrations, and sensor temperatures. Such a sensor device can also be used to characterize catalyst materials by modulating the overall sensor temperature. This could also be described by the model. The reaction kinetics for a wide range of operating temperatures could be calculated in good agreement with the measured data.

In a nutshell, this model can be used to precisely predict several interesting adjustments for sensor performance like positioning of temperature sensors, catalyst areas, other ge- 
ometry parameters, or material variations. As shown in the measurements, the sensor always needs an offset correction, which is inherent due to the sensing principle. It also depends on the fluid velocity. Possibly, an even improved model may help to develop to a system where the flow dependency can be neglected. This would be an important step forward for applications of thermoelectric sensors in transient conditions, for instance, in combustion engine exhausts as suggested by Rettig and Moos (2007) or Wu and Micheli (2004) and breath analysis (Nishibori et al., 2009; Shin et al., 2011) or wood combustion (Ojha et al., 2017).

Data availability. No data sets were used in this article.

Competing interests. The authors declare that they have no conflict of interest.

Special issue statement. This article is part of the special issue "Sensor/IRS2 2017". It is a result of the AMA Conferences, Nuremberg, Germany, 30 May-1 June 2017.

Edited by: Peter A. Lieberzeit

Reviewed by: two anonymous referees

\section{References}

Baliga, B. R. and Patankar, S. V.: A new finite-element formulation for convection-diffusion problems, Numer. Heat Tr. A-Appl., 3, 393-409, https://doi.org/10.1080/01495728008961767, 1980.

Batchelor, G. K.: Equations Governing the Motion of a Fluid, in: An Introduction to Fluid Dynamics, edited by: Batchelor, G. K., Cambridge University Press, Cambridge, 131-173, 2000.

Bentley, R. E.: The use of elemental thermocouples in hightemperature precision thermometry, Measurement, 23, 35-46, https://doi.org/10.1016/S0263-2241(98)00007-4, 1998.

Bhatia, D., McCabe, R. W., Harold, M. P., and Balakotaiah, V.: Experimental and kinetic study of NO oxidation on model Pt catalysts, J. Catal., 266, 106-119, https://doi.org/10.1016/j.jcat.2009.05.020, 2009.

Bird, R. B., Stewart, W. E., and Lightfoot, E. N.: Transport phenomena, Rev., 2. Edn., Wiley, New York, 905 pp., 2007.

Casey, V., Cleary, J., D’Arcy, G., and McMonagle, J. B.: Calorimetric combustible gas sensor based on a planar thermopile array: fabrication, characterisation, and gas response, Sensor. Actuat. B-Chem., 96, 114-123, https://doi.org/10.1016/S09254005(03)00510-0, 2003.

Chatterjee, D., Deutschmann, O., and Warnatz, J.: Detailed surface reaction mechanism in a three-way catalyst, Faraday Discussions, 119, 371-384, https://doi.org/10.1039/B101968F, 2001.

Cruickshank, D. B.: Microwave material applications: Device miniaturization and integration, Artech House microwave library, Artech House, Boston, London, 220 pp., 2017.

Deutschmann, O. and Grunwaldt, J.-D.: Exhaust Gas Aftertreatment in Mobile Systems: Status, Challenges, and Perspectives, Chem.-Ing.-Tech., 85, 595-617, https://doi.org/10.1002/cite.201200188, 2013.

Fairbanks, D. F. and Wilke, C. R.: Diffusion Coefficients in Multicomponent Gas Mixtures, Ind. Eng. Chem., 42, 471-475, https://doi.org/10.1021/ie50483a022, 1950.

Görsmann, C.: Catalytic Coatings for Active and Passive Diesel Particulate Filter Regeneration, Chemical Monthly, 136, 91-105, https://doi.org/10.1007/s00706-004-0261-z, 2005.

Groppi, G. and Tronconi, E.: Continuous vs. discrete models of nonadiabatic monolith catalysts, AICHE J., 42, 2382-2387, https://doi.org/10.1002/aic.690420829, 1996.

Guth, U. and Zosel, J.: Electrochemical solid electrolyte gas sensors - hydrocarbon and $\mathrm{NO}_{x}$ analysis in exhaust gases, Ionics, 10, 366-377, https://doi.org/10.1007/BF02377996, 2004.

Hagen, G., Leupold, N., Wiegärtner, S., and Moos, R.: Sensor Tool for Fast Catalyst Material Characterization, Top. Catal., 60, 312317, https://doi.org/10.1007/s11244-016-0617-8, 2017.

Haslach, H. W.: Electromagnetism and Joule Heating, in: Maximum Dissipation Non-Equilibrium Thermodynamics and its Geometric Structure, edited by: Haslach, H. W., Springer New York, 257-268, 2011.

Houlet, L. F., Shin, W., Tajima, K., Nishibori, M., Izu, N., Itoh, T., and Matsubara, I.: Thermopile sensor-devices for the catalytic detection of hydrogen gas, Sensor. Actuat. B-Chem., 130, 200206, https://doi.org/10.1016/j.snb.2007.07.119, 2008.

Kirchner, T. and Eigenberger, G.: On the dynamic behavior of automotive catalysts, Catal. Today, 38, 3-12, https://doi.org/10.1016/S0920-5861(97)00033-3, 1997.

Kita, J., Engelbrecht, A., Schubert, F., Groß, A., Rettig, F., and Moos, R.: Some practical points to consider with respect to thermal conductivity and electrical resistivity of ceramic substrates for high-temperature gas sensors, Sensor. Actuat. B-Chem., 213, 541-546, https://doi.org/10.1016/j.snb.2015.01.041, 2015.

Kočí, P., Štěpánek, F., Kubíček, M., and Marek, M.: Mesoscale modelling of $\mathrm{CO}$ oxidation in digitally reconstructed porous $\mathrm{Pt} / \gamma-\mathrm{Al}_{2} \mathrm{O}_{3}$ catalyst, Chem. Eng. Sci., 61, 3240-3249, https://doi.org/10.1016/j.ces.2005.12.008, 2006.

Kockmann, N., Brand, O., Fedder, G. K., Hierold, C., Korvink, J. G., and Tabata, O. (Eds.): Micro Process Engineering: Fundamentals, Devices, Fabrication, and Applications, 1. Edn., WileyVCH, Weinheim, 353-386, 2013.

Koebel, M., Elsener, M., and Kleemann, M.: Urea-SCR: a promising technique to reduce $\mathrm{NO}_{x}$ emissions from automotive diesel engines, Catal. Today, 59, 335-345, https://doi.org/10.1016/S0920-5861(00)00299-6, 2000.

McBride, B. J., Gordon, S., and Reno, M. A.: Coefficients for Calculating Thermodynamic and Transport Properties of Individual Species, NASA Technical Report, TM-4513, 1-94, 1993.

Millington, R. J.: Gas Diffusion in Porous Media, Science, 130, 100-102, https://doi.org/10.1126/science.130.3367.100-a, 1959.

Mills, K. C., Su, Y., Li, Z., and Brooks, R. F.: Equations for the Calculation of the Thermo-physical Properties of Stainless Steel, ISIJ Int., 44, 1661-1668, https://doi.org/10.2355/isijinternational.44.1661, 2004.

Miura, N., Sato, T., Anggraini, S. A., Ikeda, H., and Zhuiykov, S.: A review of mixed-potential type zirconia-based gas sensors, Ionics, 20, 901-925, https://doi.org/10.1007/s11581-014-1140$1,2014$. 
Mohanram, A., Lee, S.-H., Messing, G. L., and Green, D. J.: Constrained Sintering of Low-Temperature CoFired Ceramics, J. Am. Ceram. Soc., 89, 1923-1929, https://doi.org/10.1111/j.1551-2916.2006.01079.x, 2006.

Moos, R.: A Brief Overview on Automotive Exhaust Gas Sensors Based on Electroceramics, Int. J. Appl. Ceram. Tec., 2, 401-413, https://doi.org/10.1111/j.1744-7402.2005.02041.x, 2005.

Munro, M.: Evaluated Material Properties for a Sintered alpha-Alumina, J. Am. Ceram. Soc., 80, 1919-1928, https://doi.org/10.1111/j.1151-2916.1997.tb03074.x, 1997.

Nishibori, M., Shin, W., Izu, N., Itoh, T., and Matsubara, I.: Sensing performance of thermoelectric hydrogen sensor for breath hydrogen analysis, Sensor. Actuat. B-Chem., 137, 524-528, https://doi.org/10.1016/j.snb.2009.01.029, 2009.

O'Dwyer, A.: Handbook of PI and PID controller tuning rules, 3rd Edn., Imperial College Press, London, Singapore, 608 pp., 2009.

Ojha, B., Illyaskutty, N., Knoblauch, J., Balachandran, M. R., and Kohler, H.: High-temperature $\mathrm{CO} / \mathrm{HC}$ gas sensors to optimize firewood combustion in low-power fireplaces, J. Sens. Sens. Syst., 6, 237-246, https://doi.org/10.5194/jsss-6-237-2017, 2017.

Park, N.-H., Akamatsu, T., Itoh, T., Izu, N., and Shin, W.: Calorimetric thermoelectric gas sensor for the detection of hydrogen, methane and mixed gases, Sensors, 14, 8350-8362, https://doi.org/10.3390/s140508350, 2014.

Poling, B. E., Prausnitz, J. M., and O'Connell, J. P.: The properties of gases and liquids, 5. Edn., McGraw-Hill international editions Chemical engineering series, McGraw-Hill, New York, NY, A.1A.60, 2001.

Ramanathan, K. and Sharma, C. S.: Kinetic Parameters Estimation for Three Way Catalyst Modeling, Ind. Eng. Chem. Res., 50, 9960-9979, https://doi.org/10.1021/ie200726j, 2011.

Rettig, F. and Moos, R.: Direct thermoelectric gas sensors: Design aspects and first gas sensors, Sensor. Actuat. B-Chem., 123, 413419, https://doi.org/10.1016/j.snb.2006.09.002, 2007.
Rexeis, M. and Hausberger, S.: Trend of vehicle emission levels until 2020 - Prognosis based on current vehicle measurements and future emission legislation, Atmos. Environ., 43, 4689-4698, https://doi.org/10.1016/j.atmosenv.2008.09.034, 2009.

Riegel, J.: Exhaust gas sensors for automotive emission control, Solid State Ionics, 152-153, 783-800, https://doi.org/10.1016/S0167-2738(02)00329-6, 2002.

Russell, A. and Epling, W. S.: Diesel Oxidation Catalysts, Cataly. Rev., 53, 337-423, https://doi.org/10.1080/01614940.2011.596429, 2011.

Shin, W., Nishibori, M., Izu, N., Itoh, T., Matsubara, I., Nose, K., and Shimouchi, A.: Monitoring Breath Hydrogen Using Thermoelectric Sensor, Sens. Lett., 9, 684-687, https://doi.org/10.1166/s1.2011.1591, 2011.

Tan, Z., Sun, G., Sun, Y., Yin, A., Wang, W., Ye, J., and Zhou, L.: An adiabatic low-temperature calorimeter for heat capacity measurement of small samples, J. Therm. Anal., 45, 59-67, https://doi.org/10.1007/BF02548664, 1995.

Tsinoglou, D. N., Koltsakis, G. C., and Samaras, Z. C.: Evaluation of On-Board Diagnosis Methods for Three-Way Catalytic Converters, Environ. Sci. Technol., 36, 5270-5278, https://doi.org/10.1021/es010269y, 2002.

van Nieuwstadt, M., Upadhyay, D., and Yuan, F.: Diagnostics for Diesel Oxidation Catalysts, SAE Technical Paper, 2005-013602, https://doi.org/10.4271/2005-01-3602, 2005.

Verein Deutscher Ingenieure: VDI heat atlas, 2. Edn., VDI-Buch, Springer-Verlag, Berlin, 119-614, 2010.

Wiegärtner, S., Hagen, G., Kita, J., Reitmeier, W., Hien, M., Grass, P., and Moos, R.: Thermoelectric hydrocarbon sensor in thick-film technology for on-board-diagnostics of a diesel oxidation catalyst, Sensor. Actuat. B-Chem., 214, 234-240, https://doi.org/10.1016/j.snb.2015.02.083, 2015.

Wu, M.-C. and Micheli, A. L.: Calorimetric hydrocarbon sensor for automotive exhaust applications, Sensor. Actuat. B-Chem., 100, 291-297, https://doi.org/10.1016/j.snb.2003.11.010, 2004. 